Article

\title{
Up-Conversion Luminescence Properties of Lanthanide-Gold Hybrid Nanoparticles as Analyzed with Discrete Dipole Approximation
}

\author{
Ruichan Lv ${ }^{1,2, * \mathbb{D}}$, Miao Feng ${ }^{1}$ and Wolfgang J. Parak ${ }^{2,3} \mathbb{D}$ \\ 1 Engineering Research Center of Molecular and Neuro Imaging, Ministry of Education, School of Life Science \\ and Technology, Xidian University, Xi'an 710071, China; feng_miao@163.com \\ 2 Fachbereich Physik, Philipps Universitat Marburg, 35037 Marburg, Germany; \\ wolfgang.parak@uni-hamburg.de \\ 3 CHyN, Universität Hamburg, 22607 Hamburg, Germany \\ * Correspondence: rclv@xidian.edu.cn
}

Received: 20 October 2018; Accepted: 26 November 2018; Published: 29 November 2018

\begin{abstract}
Up-conversion nanoparticles (UCNP) under near-infrared (NIR) light irradiation have been well investigated in the field of bio-imaging. However, the low up-conversion luminescence (UCL) intensity limits applications. Plasmonic modulation has been proposed as an effective tool to adjust the luminescence intensity and lifetime. In this study discrete dipole approximation (DDA) was explored concerning guiding the design of $\mathrm{UCNP} @ \mathrm{mSiO}_{2}-\mathrm{Au}$ structures with enhanced UCL intensity. The extinction effects of gold shells could be changed by adjusting the distance between the UCNPs and the Au NPs by synthesized tunable mesoporous silica $\left(\mathrm{mSiO}_{2}\right)$ spacers. Enhanced UCL was obtained under $808 \mathrm{~nm}$ irradiation. The original theoretical predictions could not be demonstrated to full extend by experimental data, indicating that better models for simulation need to take into account in homogeneities in particle morphologies. Yet, one very certain conclusion resulting from the DDA calculations and experiments is that the absorbance can blue-shift with more $\mathrm{Au}$ NPs added and the absorbance can-red shift for samples with enhanced silica sizes in the UCNP@ $\mathrm{mSiO}_{2}$-Au structures. Furthermore, when the DDA model is more consistent with the practical structure (dispersed Au NPs instead of Au shell), the theoretical absorbance occurs almost the same as the practical absorbance. All in all, the DDA could fit the extinction effect of Au perfectly and be suitable for guiding how to design the UCNP and Au.
\end{abstract}

Keywords: up conversion nanoparticles; discrete dipole approximation; surface plasmon resonance; lanthanide-based composites

\section{Introduction}

In the context of bio-imaging lanthanide-based composites have been heavily investigated, including their synthesis, up-conversion luminescence (UCL) properties, and long-term cytotoxicity [1-9]. Especially, up-conversion nanoparticles (UCNPs) have been proposed as effective optical nano-probes because of the possibility to excite them in the near-infrared (NIR), which allows for deep tissue penetration, and almost negligible self-fluorescence [10-13]. In more recent years, $\mathrm{Nd}^{3+}$-sensitized UCL materials were proposed using $808 \mathrm{~nm}$ light as alternative irradiation source, which has the merit to reduce overheating of cells and to improve the penetration depth [14-16]. However, the low UCL efficiency is still an important problem that hinders its further application in bio-imaging [17].

Metal modulation is an important way to improve the luminescence efficiency. Metal nanoparticles, in particular gold nanoparticles (Au NPs) exhibit surface plasmon resonance 
(SPR) [18-20], i.e., when the oscillating frequency of free electrons on the metal surface is consistent with the photon frequency of the incident light, an energy resonance phenomenon occurs. The SPR effect depends on size and morphology of the Au [21,22]. Various extinction (i.e., absorption and scattering) properties of Au NPs have been used in different applications, such as scattering, dark field, and two-photon based optical imaging [23-25]. When $\mathrm{Au}$ is combined with up-conversion luminescent NPs, the scattering and absorption in the crossing visible area impairs the luminescence emission. It is proposed that all UCL peaks could be enhanced if the SPR peak would be tuned to the NIR region $[26,27]$.

A theory to guide the design of such UCNP@Au structures would be helpful to achieve higher UCL intensities. In a previous study, we found that discrete dipole approximation (DDA) could be well used to simulate the SPR effect of gold NPs, and that there is a good agreement with measured optical properties $[28,29]$. On basis of this, in the present study we expand the DDA method to calculate the optical properties of lanthanide-metal nanostructures. Note that DDA permits calculation for arbitrary shapes. Although there were literatures about the combination of $\mathrm{UCNP}$ and $\mathrm{SiO}_{2}$ using the plasmonic enhancement of the gold nanoparticles [30,31], there was still no literature using DDA to guide the design of UCNP@mSiO ${ }_{2} @ \mathrm{Au}$ composites' structure. It is significant if the DDA simulation results could be well coincident with the real detected data. Even though there would be some disagreement between the simulation and the experimental, the simulation still has a meaningful inspiration to guide to synthesize the proper structure.

Herein, we use the discrete dipole approximation to guide the design of UCNP@mSiO 2 -AuNP structures for an enhanced UCL emission. The extinction effects of the gold shells were changed by adjusting the distance between the center UCNPs and surrounding Au NPs by a tunable mesoporous silica spacer. Finally, the enhanced UCL under $808 \mathrm{~nm}$ irradiation was experimentally verified. The present study exemplifies the employment of theoretical approaches (i.e., DDA) to describe the optical properties of gold and up-conversion luminescent NPs, in order to achieve a better understanding of the behavior of lanthanide-metal hybrid NPs.

\section{Experimental Section}

\subsection{Reagents and Materials}

Yttrium oxide $\left(\mathrm{Y}_{2} \mathrm{O}_{3}, 99.99 \%\right)$, ytterbium oxide $\left(\mathrm{Yb}_{2} \mathrm{O}_{3}, 99.9 \%\right)$, neodymium oxide $\left(\mathrm{Nd}_{2} \mathrm{O}_{3}\right.$, 99.99\%), yttrium chloride $\left(\mathrm{YCl}_{3} \cdot 6 \mathrm{H}_{2} \mathrm{O}, 99.99 \%\right)$, ytterbium chloride $\left(\mathrm{YbCl}_{3} \cdot 6 \mathrm{H}_{2} \mathrm{O}, 99.99 \%\right)$, neodymium chloride $\left(\mathrm{NdCl}_{3} \cdot 6 \mathrm{H}_{2} \mathrm{O}, 99.9 \%\right)$, oleic acid $(90 \%$, tech grade), octadecene $(90 \%$, tech grade), trifluoroacetic acid $\left(\mathrm{CF}_{3} \mathrm{COOH}, 99 \%\right)$, sodium trifluoroacetate $\left(\mathrm{CF}_{3} \mathrm{COONa}, 98 \%\right)$, methanol $(\geq 99.8 \%)$, hexane ( $\geq 98.5 \%)$, ammonia fluoride $\left(\mathrm{NH}_{4} \mathrm{~F}, \geq 99.99 \%\right)$, sodium hydroxide $(\mathrm{NaOH}$, anhydrous, $\geq 97 \%)$, citric acid $\left(\mathrm{H}_{3} \mathrm{Cit}\right)$, chloroauric acid $\left(\mathrm{HAuCl}_{4}\right)$, hexadecyl trimethyl ammonium bromide (CTAB, $\left.99 \%\right)$, tetraethyl orthosilicate (TEOS, 99.99\%), and aminopropyltriethoxysilane (APTES, molecular weight: 1800, 99\%) were obtained by Shanghai Aladdin Bio-Chem Technology Co., Ltd., Shanghai, China. Ammonia water (25-28\%) was purchased from Tianjin Kermel Chemical Reagent Co., Ltd., Tianjin, China. All chemical reagents were used as received without any further purification.

\subsection{Synthesis of $\mathrm{NaYF}_{4}: 18 \% \mathrm{Yb}, 2 \% \mathrm{Er}$}

The synthesis process was carried out following a previously published protocol [2]. Note that all of the synthesis was under argon atmosphere. Typically, 0.8/0.18/0.02 $\mathrm{mmol}$ of $\mathrm{YCl}_{3} / \mathrm{YbCl}_{3} / \mathrm{ErCl}_{3}$, $10 \mathrm{~mL}$ of oleic acid, and $15 \mathrm{~mL}$ of octadecene were mixed in a three-necked bottle. The mixture was heated to $160^{\circ} \mathrm{C}$ and kept for $1 \mathrm{~h}$ to obtain a clear yellow solution (Solution A). 4 mmol NH $4 \mathrm{~F}, 2.5 \mathrm{mmol}$ of $\mathrm{NaOH}$ was mixed together with $10 \mathrm{~mL}$ of methonal and sonicated for $10 \mathrm{~min}$ to obtain a clear solution (Solution B). Solution B was injected into the three-neck bottle directly after Solution A cooled down, and stirred for another $30 \mathrm{~min}$ under the room temperature. Then, the mixed solution was heated and kept at $100{ }^{\circ} \mathrm{C}$ for $20 \mathrm{~min}$ to remove the methanol. After that, the solution was heated 
to $300{ }^{\circ} \mathrm{C}$ and kept for $1 \mathrm{~h}$. Finally, the solution was washed and centrifuged with ethanol to obtain $\mathrm{NaYF}_{4}: 18 \% \mathrm{Yb}, 2 \% \mathrm{Er}$ NPs. The NP precipitate was finally dissolved in hexane.

\subsection{Synthesis of Core/Shell $\mathrm{NaYF}_{4}: 18 \% \mathrm{Yb}, 2 \% \mathrm{Er} @ \mathrm{NaYF}_{4}: 30 \% \mathrm{Yb}, 10 \% \mathrm{Nd}$}

Following the previously published protocol [2], $0.6 \mathrm{mmol}$ of $\mathrm{Y}_{2} \mathrm{O}_{3}, 0.3 \mathrm{mmol}$ of $\mathrm{Nd}_{2} \mathrm{O}_{3}$, and $0.1 \mathrm{mmol}$ of $\mathrm{Yb}_{2} \mathrm{O}_{3}$ were mixed in a three-necked bottle with $5 \mathrm{~mL}$ of $\mathrm{CF}_{3} \mathrm{COOH}$ and heated at $120{ }^{\circ} \mathrm{C}$ until lanthanide trifluoroacetic powder was precipitated in the bottom of the bottle. Then, the as-synthesized $\mathrm{NaYF}_{4}: 18 \% \mathrm{Yb}, 2 \% \mathrm{Er}$ NPs dissolved in hexane was added into the bottle, together with $10 \mathrm{~mL}$ of oleic acid and $15 \mathrm{~mL}$ of octadecene. After further heating and stirring at $120{ }^{\circ} \mathrm{C}$ for $30 \mathrm{~min}$, the clear solution was heated and kept at $310^{\circ} \mathrm{C}$ for another $30 \mathrm{~min}$. Finally, the solution was washed and centrifuged with ethanol and the $\mathrm{NaYF}_{4}: 18 \% \mathrm{Yb}, 2 \% \mathrm{Er} @ \mathrm{NaYF}_{4}: 30 \% \mathrm{Yb}, 10 \% \mathrm{Nd} \mathrm{NPs}$ were dissolved in hexane for further use.

\subsection{Synthesis of Mesoporous UCNP@mSiO 2}

Following a previously published protocol [2], the oleic acid-capped UCNPs were firstly rendered hydrophilic by using CTAB. Typically, 2 mL of $\mathrm{NaYF}_{4}: 18 \% \mathrm{Yb}, 2 \% \mathrm{Er} @ \mathrm{NaYF}_{4}: 30 \% \mathrm{Yb}, 10 \% \mathrm{Nd}$ dissolved in hexane and $0.1 \mathrm{~g}$ of CTAB was mixed with $10 \mathrm{~mL}$ ethanol and $40 \mathrm{~mL}$ of deionized water under continuous stirring. After stirring for $12 \mathrm{~h}$, the hexane was removed and the solution turned to be clear. Then, $1 \mathrm{~mL}$ of pure ammonia water $(25-28 \%)$ was added. The mixture was heated and kept at $70{ }^{\circ} \mathrm{C}$, and $150 \mu \mathrm{L}$ of TEOS was added slowly. After $10 \mathrm{~min}$ reaction, the mixture was centrifuged and washed with ethanol and water for several times. The samples with different silica thickness were synthesized by adjusting the amount of TEOS $(0.15 \mathrm{~mL}, 0.17 \mathrm{~mL}, 0.20 \mathrm{~mL}$, and $0.30 \mathrm{~mL})$. To obtain the mesoporous silica shell, the CTAB surfactant should be removed further. Typically, the as-synthesized silica-coated NPs were mixed with $30 \mathrm{~mL}$ of ethanol with $0.3 \mathrm{~g}$ of $\mathrm{NH}_{4} \mathrm{NO}_{3}$, and then kept at $60^{\circ} \mathrm{C}$ for $2 \mathrm{~h}$. Then, the solution was centrifuged with ethanol three times and the NP precipitate was collected (denoted as UCNP@ $\mathrm{mSiO}_{2}$ in the following).

\subsection{Synthesis of Mesoporous UCNP@mSiO $2-A u$}

$\mathrm{UCNP} @ \mathrm{mSiO}_{2} \mathrm{NPs}$ were dispersed in $20 \mathrm{~mL}$ of deionized water and then mixed with $0.1 \mathrm{~mL}$ of APTES solution. After stirring for $2 \mathrm{~h}$ at $45^{\circ} \mathrm{C}$, the solution was centrifuged and the NP precipitate was washed with deionized water. $400 \mu \mathrm{L}$ of $\mathrm{HAuCl}_{4}(1 \mathrm{~g} / \mathrm{L})$ mixed with $45 \mathrm{mg}$ of sodium citrate were stirred for $20 \mathrm{~min}$ at room temperature in $20 \mathrm{~mL}$ of deionized water, and then $0.1 \mathrm{~mol}^{\circ} \mathrm{NaBH}_{4}$ solution (kept in ice water) were added quickly into the solution to obtain the gold NPs. Then, the sample was mixed with $4 \mathrm{~mL}$ of the obtained gold nanoparticles for another $2 \mathrm{~h}$ at room temperature.

\subsection{Characterization}

Images of the morphology of the NPs were obtained digitally with scanning electron microscopy (SEM, JSM-6480A, Xi' an, Shaanxi, China) and transmission electron microscopy (TEM; FEI Tecnai G2 STwin, Xi' an, Shaanxi, China). Absorbance spectra were recorded with an UV-1601 ultraviolet visible (UV-vis) spectrophotometer. UCL emission spectra were obtained on an Edinburgh FLS980 apparatus using a $980 \mathrm{~nm}$ laser diode module (MDL-III-980-2W) as irradiation source and recording in the visible light region.

\subsection{DDA Simulation}

The DDA calculation was carried out by DDSCAT in the Windows 10, and it starts by dividing the $\mathrm{NaYF}_{4}$ core@mSiO 2 shell-Au shell into a cubic array of $\mathrm{N}$-point dipoles. The refractive index dispersion of $\mathrm{NaYF}_{4} @ \mathrm{mSiO}_{2}-\mathrm{Au}$ spheres with different visible/near-infrared wavelengths (300-1000 nm) were used (as shown in Figure S1 and Tables S1-S3). The extinction (absorbance and scattering) effect could be obtain after processed iteratively among polarizable dipoles in the cells, and detected at the 
wavelength of 300-1000 $\mathrm{nm}$. DDA process is converged with the error tolerance less than $10^{-5}$ when the number of dipoles larger than one thousand in order to ensure accuracy.

\section{Results and Discussion}

The schematic diagram of the synthesis process of $\mathrm{UCNP} @ \mathrm{mSiO}_{2}-\mathrm{Au}$ hybrid NPs is shown in Scheme 1. The structure consists of the UCNP core (radius $R_{1}$ ), the mesoporous silica shell (thickness $D)$, and then the shell of gold NPs grown on top of the mesoporous silica (thickness Z).

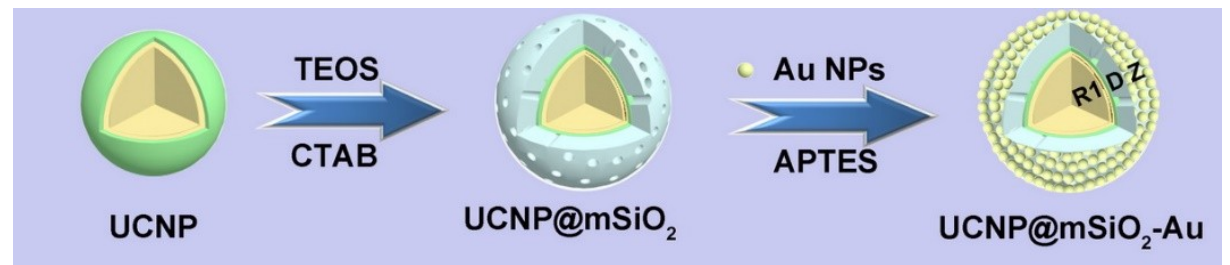

Scheme 1. Sketch of the synthesis of UCNP@mSiO ${ }_{2}-\mathrm{Au}$ NPs. The radius of the UCNP core is $R_{1}$, the thickness of the silica shell $D$, and the thickness of the layer of Au NPs is Z. In this way the radius of UCNP@mSiO 2 is $R_{2}=R_{1}+D$ and the radius of $\mathrm{UCNP} @ \mathrm{mSiO}_{2}-\mathrm{Au}$ is $R_{3}=R_{1}+D+Z$.

TEM images of $\mathrm{NaYF}_{4}: \mathrm{Yb}, \mathrm{Er}$ and $\mathrm{NaYF}_{4}: \mathrm{Yb}, \mathrm{Er} @ \mathrm{NaYF}_{4}: \mathrm{Yb}, \mathrm{Nd}$ UCNPs are shown in Figure 1A,B. The radius $R_{1}$ of the $\mathrm{NaYF}_{4}: Y b$,Er NPs is about $11 \mathrm{~nm}$. After further epitaxial growth, the radius $\mathrm{R}_{1}$ of the $\mathrm{NaYF}_{4}: \mathrm{Yb}$,Er@NaYF $4: \mathrm{Yb}, \mathrm{Nd} \mathrm{NPs}$ is around $15 \mathrm{~nm}$. TEM images of the as-prepared $\mathrm{UCNP}_{\mathrm{N}} \mathrm{mSiO}_{2}$ samples with different mesoporous silica shells are shown in Figure 1C-F. Examples of shell thicknesses D with $5 \mathrm{~nm}, 15 \mathrm{~nm}, 30 \mathrm{~nm}$, and $60 \mathrm{~nm}$ are shown. This demonstrates that the thickness of the silica shell could be well adjusted by adjusting the added amount of TEOS. In Figure 1G1-G3, images of UCNP@mSiO $\mathrm{m}_{2}$-Au NPs $(D=30 \mathrm{~nm})$ are shown. As shown in Figure 2A,B, the Au NPs could be clearly found on the surface and in the mesoporous shell of silica. The energy-dispersive X-ray spectroscopy (EDS) results of $\mathrm{UCNP@mSiO} 2$-Au NPs $(D=15 \mathrm{~nm})$ are presented in Figure $2 \mathrm{C}$, which show presence of $\mathrm{Na}, \mathrm{Y}, \mathrm{Yb}, \mathrm{Nd}$. F, Si, and Au. Furthermore, SEM images at different magnifications and high-angle annular dark-field scanning transmission electron microscopy (STEM) images of UCNP@mSiO $\mathrm{m}_{2}-\mathrm{Au}$ NPs $(D=30 \mathrm{~nm})$ are shown in Figure $3 \mathrm{~A} 1, \mathrm{~A} 2, \mathrm{~B}$, respectively. The line scanning intensity and map scanning images of $\mathrm{UCNP} @ \mathrm{mSiO}_{2}-\mathrm{Au} \mathrm{NPs}(D=30 \mathrm{~nm})$ in Figure $3 \mathrm{C} 1,3 \mathrm{C} 2$ indicate the distinct distribution of the UCNP core and silica mesoporous shell. The thickness $Z$ of the layer of the Au NPs was $2-4 \mathrm{~nm}$ (as shown in Figures 2 and 3). The silica shell was acting as spacer between the UCNP core and the Au NP shell. The nomenclature of the NPs with different UCNP core radius $R_{1}$, silica shell with thickness $D$, and Au NP shell with thickness $Z$ is termed $R_{1}-D-Z$.

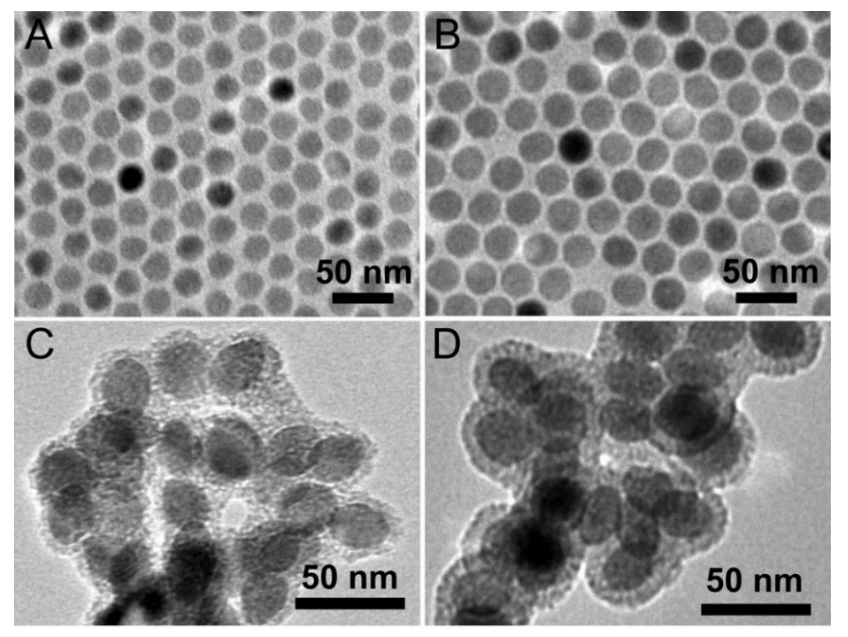

Figure 1. Cont. 


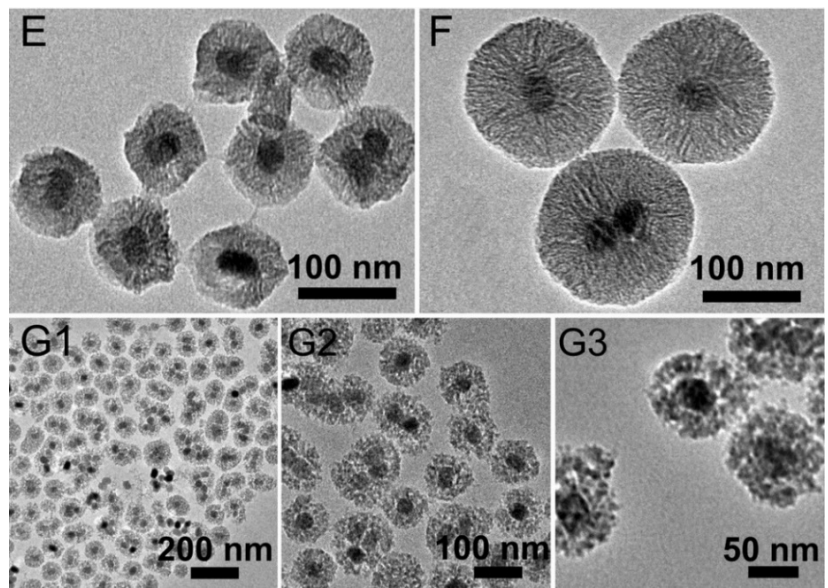

Figure 1. TEM images of (A) $\mathrm{NaYF}_{4}: \mathrm{Yb}$,Er and (B) $\mathrm{NaYF}_{4}: \mathrm{Yb}, \mathrm{Er} @ \mathrm{NaYF}_{4}: \mathrm{Yb}, \mathrm{Nd}$ UCNPs. TEM images of $\mathrm{UCNP} @ \mathrm{mSiO}_{2}\left(R_{1}=15 \mathrm{~nm}\right)$ with different mesoporous silica sizes: (C) $D=5 \mathrm{~nm}$, (D) $15 \mathrm{~nm}$, (E) $30 \mathrm{~nm}$, and (F) $60 \mathrm{~nm}$. (G1-G3) TEM images of UCNP@mSiO ${ }_{2}-\mathrm{Au}$ NPs $\left(R_{1}=15 \mathrm{~nm}, D=30 \mathrm{~nm}\right.$, $\mathrm{Z}=2-4 \mathrm{~nm})$ at different magnifications.
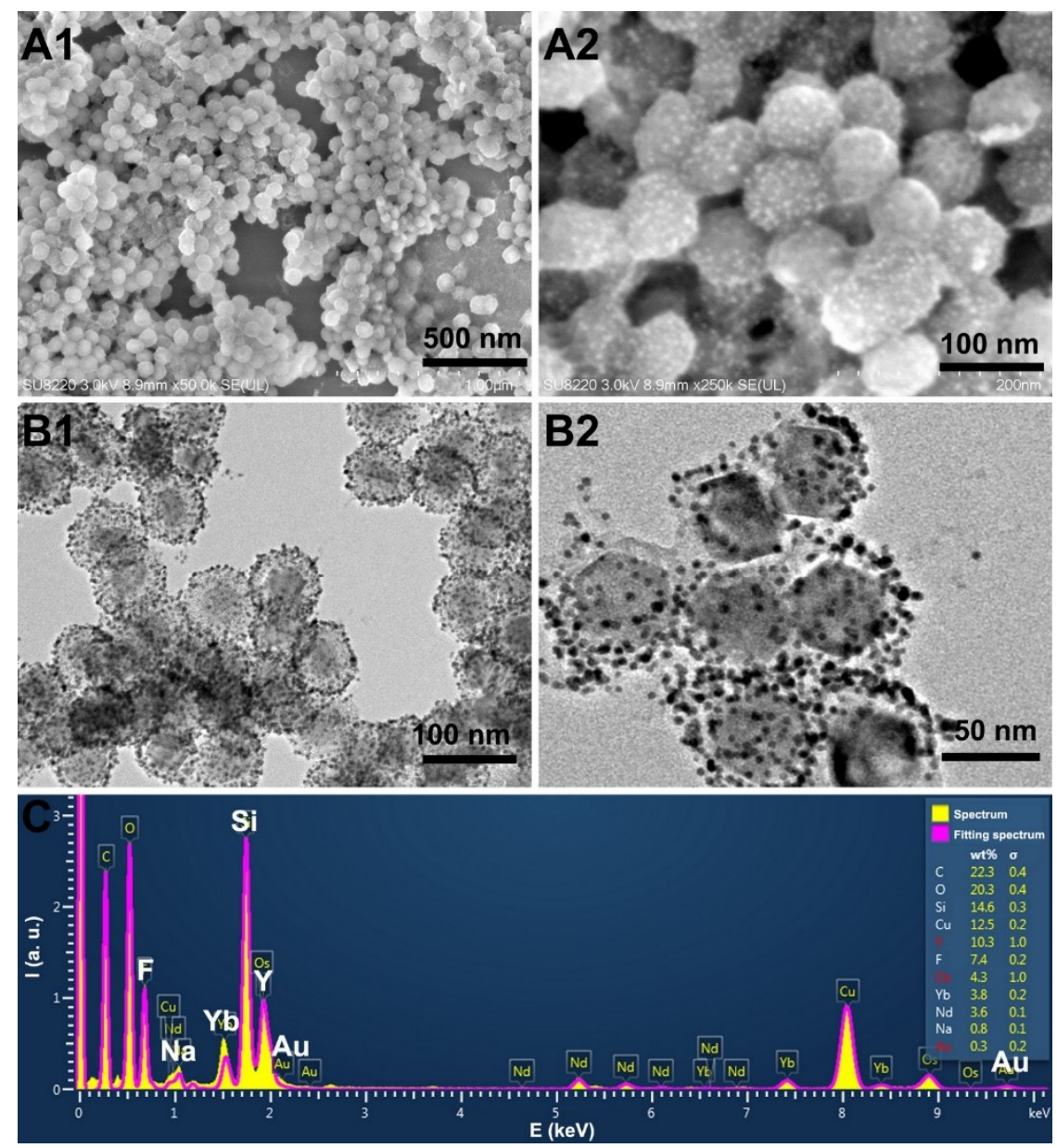

Figure 2. (A1,A2) SEM images at different magnifications, (B1,B2) TEM images at different magnifications, and (C) EDS result of UCNP@mSiO 2 -Au NPs $\left(R_{1}=15 \mathrm{~nm}, D=15 \mathrm{~nm}, Z=2-4 \mathrm{~nm}\right)$, in which the intensity peaks in the $\mathrm{I}(\mathrm{E})$ curve correspond to the differences in energy $\mathrm{E}$ between two states of the electron shell which are characteristic to the atomic structure of the emitting element. 

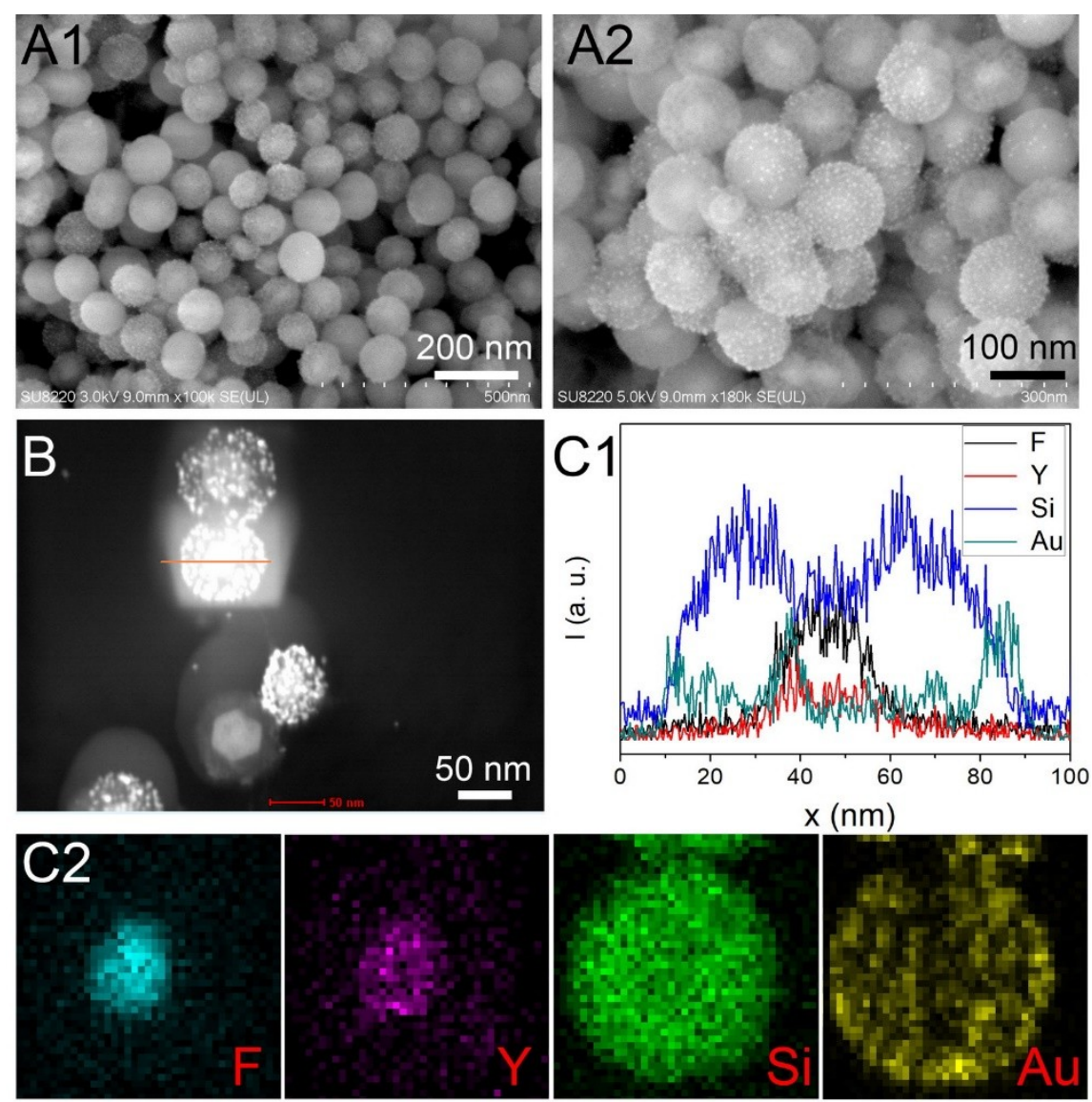

Figure 3. (A1,A2) SEM images at different magnifications, (B) High-angle annular dark-field scanning transmission electron microscopy (STEM) images, (C1) line scanning intensity $I(x)$ with $x$ indicating the position, and (C2) map scanning images of $\mathrm{UCNP@mSiO}{ }_{2}-\mathrm{Au} \mathrm{NPs}\left(R_{1}=15 \mathrm{~nm}, D=30 \mathrm{~nm}\right.$, $Z=2-4 \mathrm{~nm})$.

The DDA method was used to perform in accordance to previous studies [28,29]. The electro-dynamic simulations using the dielectric functions of the confined gold and $\mathrm{NaYF}_{4}$ parts were as inputs. Figure 4A shows the final extinction curves of UCNP-Au NPs (i.e., NPs without silica spacer, $D=0$ ) for UCNP cores with radius $R_{1}=15 \mathrm{~nm}$ with different sizes of the Au NPs shell, as derived using DDA simulations. It is known that for nanoscale structures scattering is usually much smaller than absorption, and therefore the latter dominates the optical response. As shown in Figure $4 \mathrm{~B}$, for the UCNP-Au NPs with $Z=5 \mathrm{~nm}$ (i.e., the whole radius $R_{2}=R_{1}+D+Z=15 \mathrm{~nm}+$ $0+5 \mathrm{~nm}=20 \mathrm{~nm}$ ), the scattering is very weak and can be basically ignored. When the thickness of the $\mathrm{Au} N P$ shell increases to $Z=15 \mathrm{~nm}$ and $30 \mathrm{~nm}$, the scattering increases (Figure 4C,D). As known that the increased scattering effect of the composite in the visible emission region would be harmful to the final UCL intensity. Also, one can see that the SPR peak of the Au NP shell is blue-shifted (from $\lambda_{\mathrm{SPR}}=570 \mathrm{~nm}$ to $\lambda_{\mathrm{SPR}}=520 \mathrm{~nm}$ ) with increasing $Z$. Thus, a thickness of the Au NPs shell with $\mathrm{Z}=5 \mathrm{~nm}$ is favorable and is used in the following. 

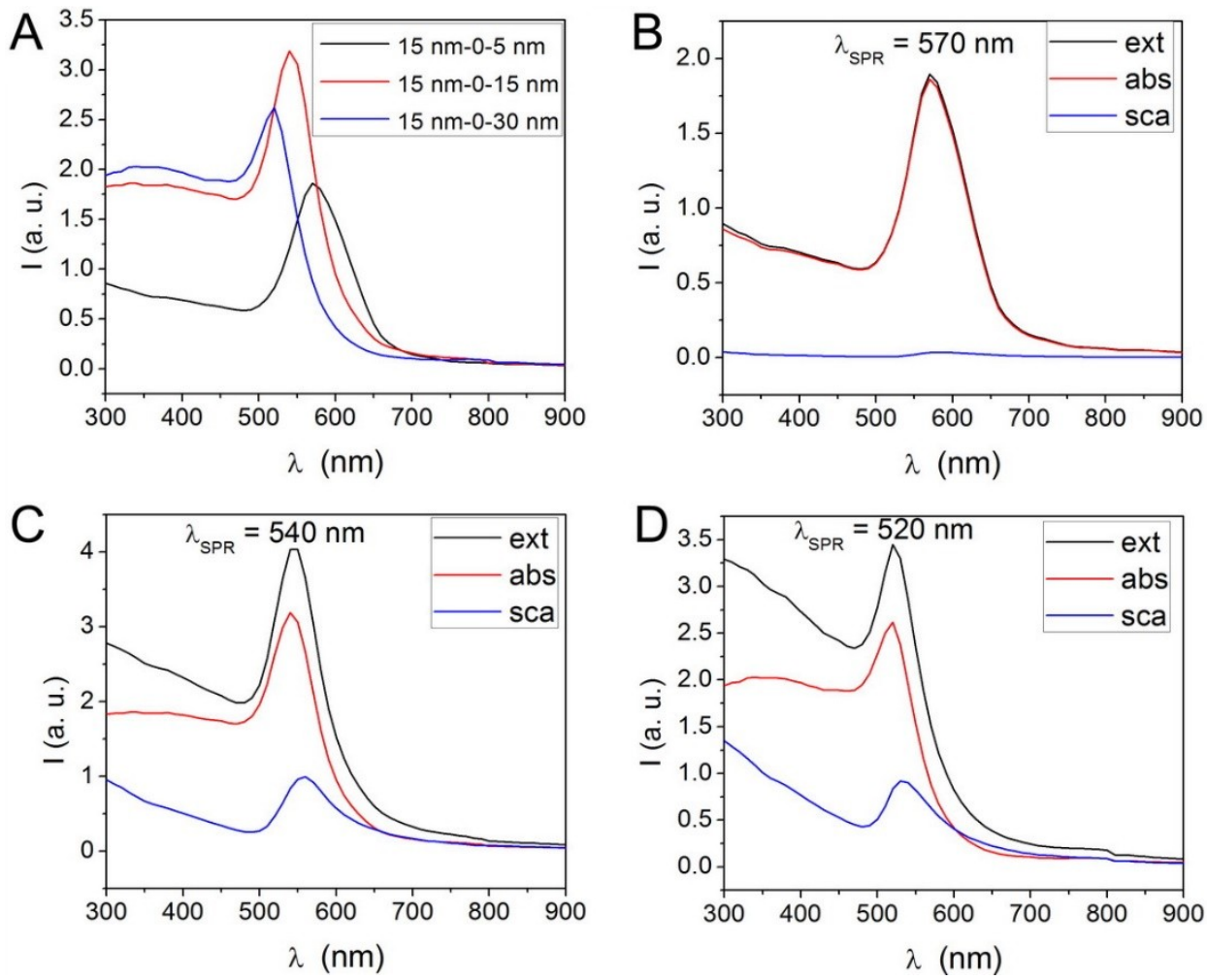

Figure 4. DDA simulation results $I(\lambda)$, referring to the wavelength-dependence of extinction (ext), absorption (abs), and scattering (sca). (A) The extinction curves of UCNP-Au NPs with different Au NP shell sizes, with geometry $R_{1}-0-Z$. The contribution of absorbance and scattering to the extinction curves is shown for (B) $15 \mathrm{~nm}-0-5 \mathrm{~nm},(\mathbf{C}) 15 \mathrm{~nm}-0-15 \mathrm{~nm}$, and (D) $15 \mathrm{~nm}-0-30 \mathrm{~nm}$ geometry.

To obtain a hybrid structure with tunable SPR wavelength $\lambda_{\mathrm{SPR}}$, a spacer of mesoporous silica with adjustable distance D between the UCNP core and the Au NP shell was introduced. The extinction curves of UCNP@ $\mathrm{mSiO}_{2}$-Au NPs with different silica shells as calculated by DDA simulation are shown in Figure 5A. There is an obvious red shift of the SPR peak when the thickness of the silica spacer is increased. The extinction (absorbance and scattering) curves of UCNP@ $\mathrm{mSiO}_{2}-\mathrm{Au} \mathrm{NPs}_{\mathrm{sith}}$ different shell thicknesses of $D=0 \mathrm{~nm}, 5 \mathrm{~nm}, 15 \mathrm{~nm}, 30 \mathrm{~nm}$, and $60 \mathrm{~nm}$ are presented in Figure 5B-F. The wavelengths of the corresponding SPR peaks are $\lambda_{\mathrm{SPR}}=570 \mathrm{~nm}, 590 \mathrm{~nm}, 640 \mathrm{~nm}, 730 \mathrm{~nm}$, and $880 \mathrm{~nm}$, respectively. The results indicate that the adjustable silica spacer size has an obvious influence on the final optical extinction.

In order to better visualize the optical properties of the lanthanide-gold hybrid NPs, the electric

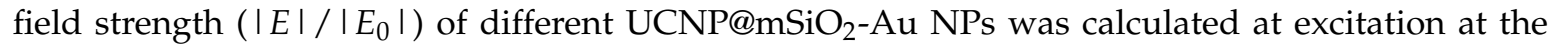
SPR resonance $\lambda_{\mathrm{exc}}=\lambda_{\mathrm{SPR}}$ and at $\lambda_{\mathrm{exc}}=808 \mathrm{~nm}$, which would be the envisaged excitation in bioimaging experiments. As presented in Figure 6, when the distance between UCNP core and the gold NP shell is $30 \mathrm{~nm}$, there is the strongest field strength at the excitation peak at $808 \mathrm{~nm}$ and SPR peak. DDA simulations thus predict $15 \mathrm{~nm}-30 \mathrm{~nm}-5 \mathrm{~nm}$ as the most favorable UCNP@mSiO${ }_{2}-\mathrm{Au}$ NP structure. 
A
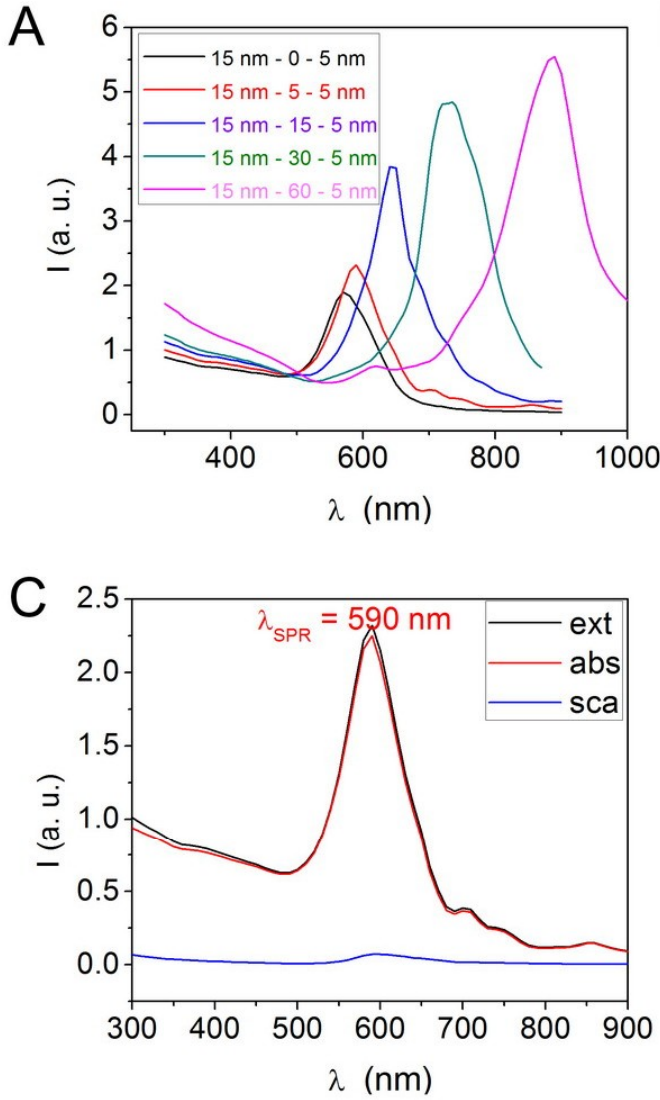

E

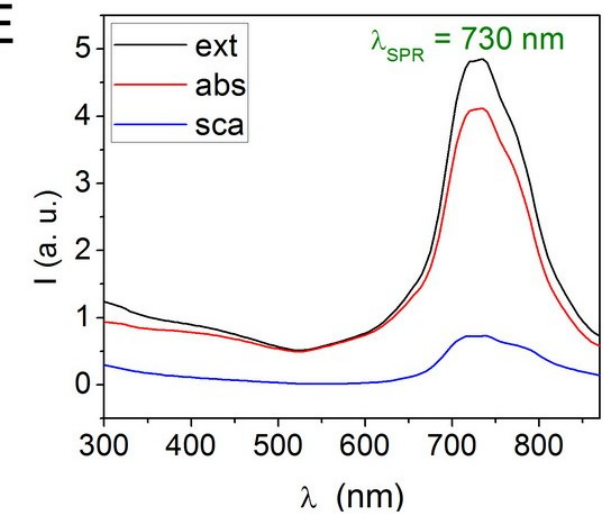

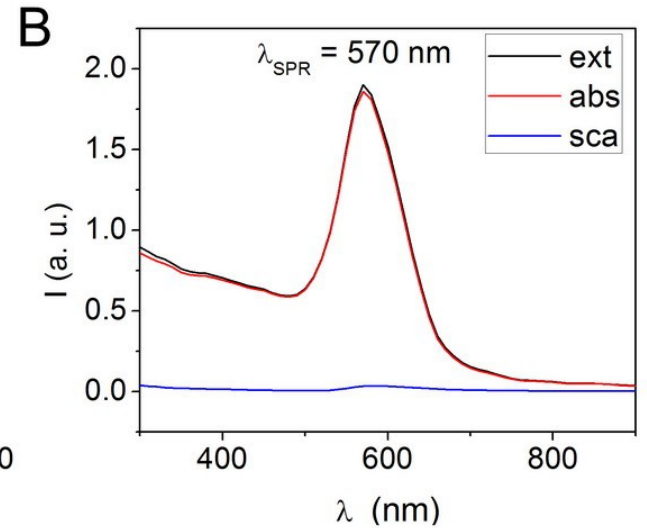

D
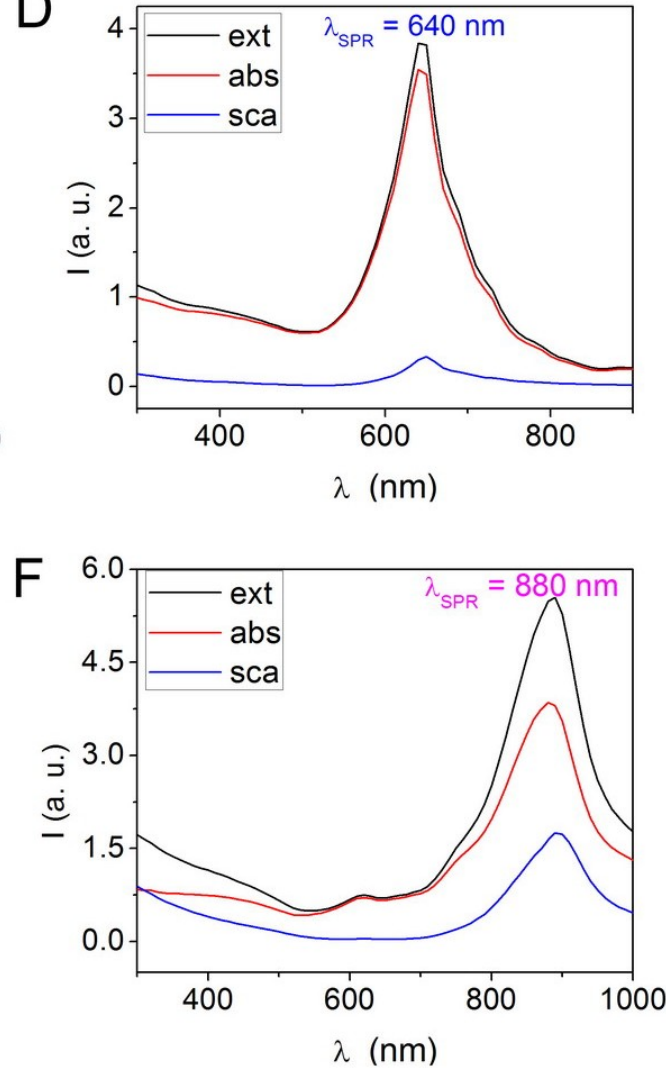

Figure 5. DDA simulation results $I(\lambda)$, referring to the wavelength-dependence of extinction (ext), absorption (abs), and scattering (sca). (A) The extinction curves of $\mathrm{UCNP@mSiO}{ }_{2}$-Au NPs with different silica shell thickness $D$. The extinction (absorbance and scattering) curves of $\mathrm{UCNP} @ \mathrm{mSiO}_{2}-\mathrm{Au} \mathrm{NPs}$ with silica shell thickness $D$ of (B) $0 \mathrm{~nm},(\mathbf{C}) 5 \mathrm{~nm},(\mathbf{D}) 15 \mathrm{~nm},(\mathbf{E}) 30 \mathrm{~nm}$, and (F) $60 \mathrm{~nm}$.

In order to verify the DDA predictions the UCL spectra of as-synthesized UCNP@mSiO ${ }_{2}-\mathrm{Au} \mathrm{NPs}$ with different silica spacer thicknesses (cf. Figure 1) were measured. The spectra of $\mathrm{UCNP} @ \mathrm{mSiO}_{2}-\mathrm{Au}$ NPs contained four chief emission peaks at around 409,521,543, and $654 \mathrm{~nm}$, corresponding to the ${ }^{2} \mathrm{H}_{9 / 2} \rightarrow 4 \mathrm{I}_{15 / 2},{ }^{2} \mathrm{H}_{11 / 2} \rightarrow{ }^{4} \mathrm{I}_{15 / 2},{ }^{4} \mathrm{~S}_{3 / 2} \rightarrow{ }^{4} \mathrm{I}_{15 / 2}$, and ${ }^{4} \mathrm{~F}_{9 / 2} \rightarrow{ }^{4} \mathrm{I}_{15 / 2}$ transitions of $\mathrm{Er}^{3+}$, respectively (Figure 7A). One can see that for a mesoporous silica spacer of thickness $D=30 \mathrm{~nm}$, the UCL intensity at excitation $\lambda_{\mathrm{exc}}=808 \mathrm{~nm}$ enhanced more than 2-fold for different emission wavelengths $\lambda_{\mathrm{em}}$ (Figure 7B): 2.61-fold $\left(\lambda_{\mathrm{em}}=409 \mathrm{~nm}\right), 2.96$-fold $\left(\lambda_{\mathrm{em}}=543 \mathrm{~nm}\right)$, and 2.18-fold $\left(\lambda_{\mathrm{em}}=645 \mathrm{~nm}\right)$, respectively. In this way the experimental data verify the predictions as achieved by DDA simulations. However, when we detected the actual absorbance properties of the solutions with different Au NPs added and with 
different distances between the UCNPs and Au NPs the results did not fully match the predictions (Figure 8A compared with Figure 4A, Figure 8B compared with Figure 5A).

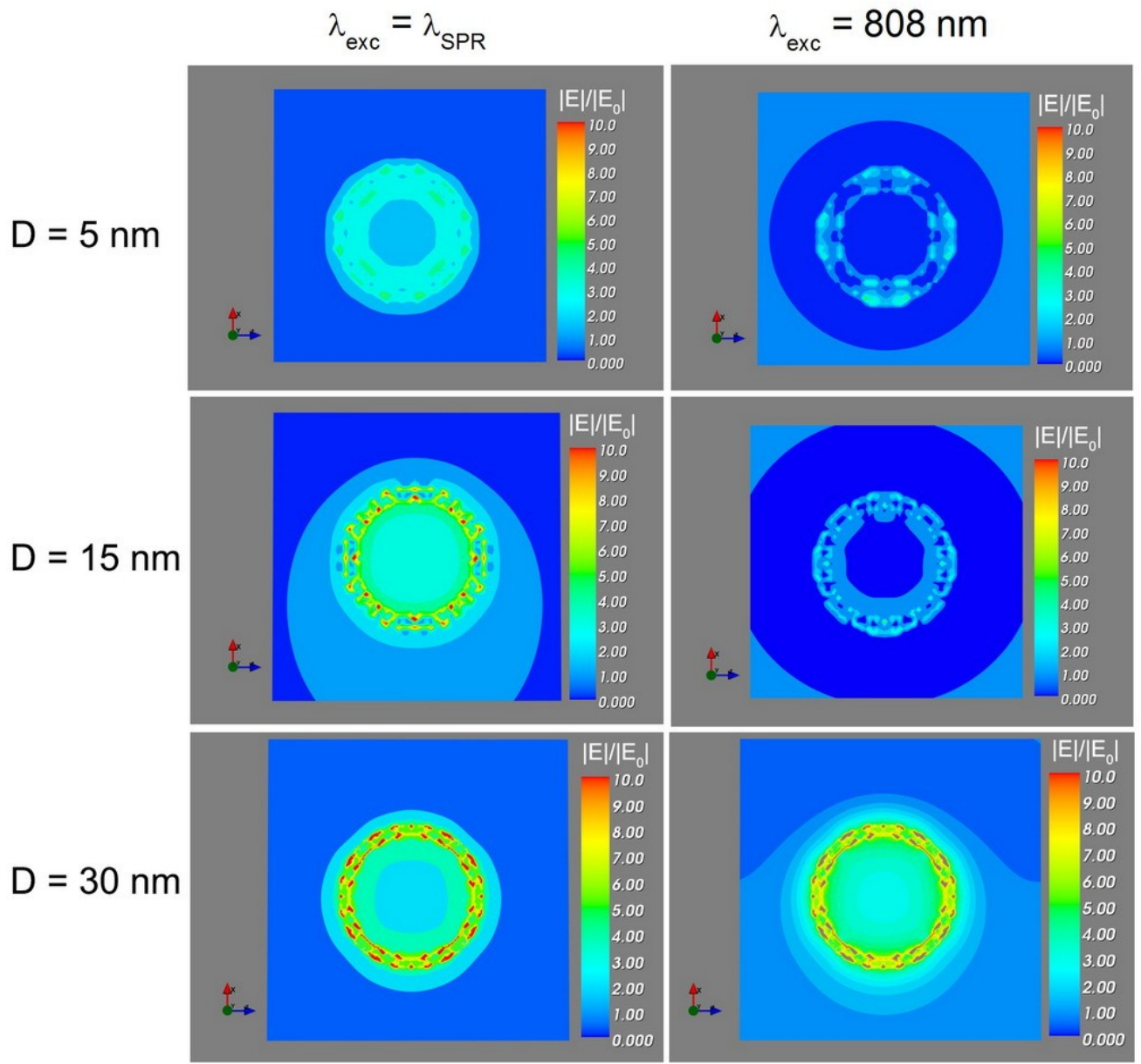

Figure 6. Simulation of the electric field strength $\left(|E| /\left|E_{0}\right|\right)$ of $\mathrm{UCNP}_{\mathrm{mSiO}}-\mathrm{Au} \mathrm{NPs}$ (15 nm-D-5 nm geometry) under the irradiation wavelength $\lambda_{\text {exc }}=\lambda_{\text {SPR }}$ and $\lambda_{\text {exc }}=800 \mathrm{~nm}$, with different silica spacers with thickness $D$ of $5 \mathrm{~nm}, 15 \mathrm{~nm}$, and $30 \mathrm{~nm}$. $|E| /\left|E_{0}\right|$ is the enhancement factor. The electric field is amplified in case $|E|>\left|E_{0}\right|$.
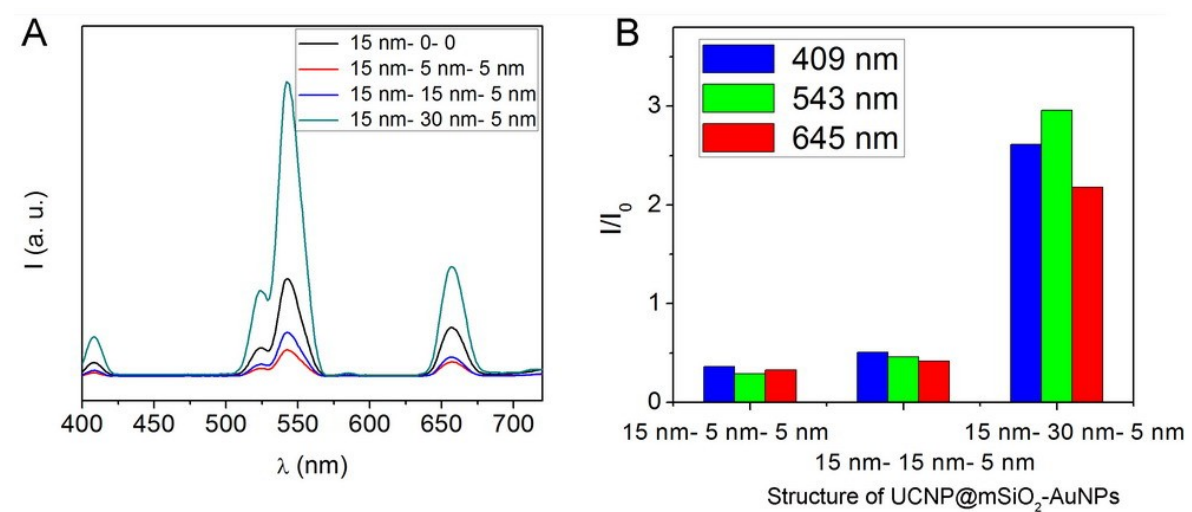

Figure 7. (A) Experimental UCL spectra $I(\lambda)$ of $U C N P @ m S i O_{2}-A u$ NPs with different structure and (B) the corresponding enhancement factor $I / I_{0}$ corresponding to the intensity maxima at the different emission regions. $I_{0}$ refers to the intensity of the plain UCNPs (geometry $15 \mathrm{~nm}-0-0$ ). 

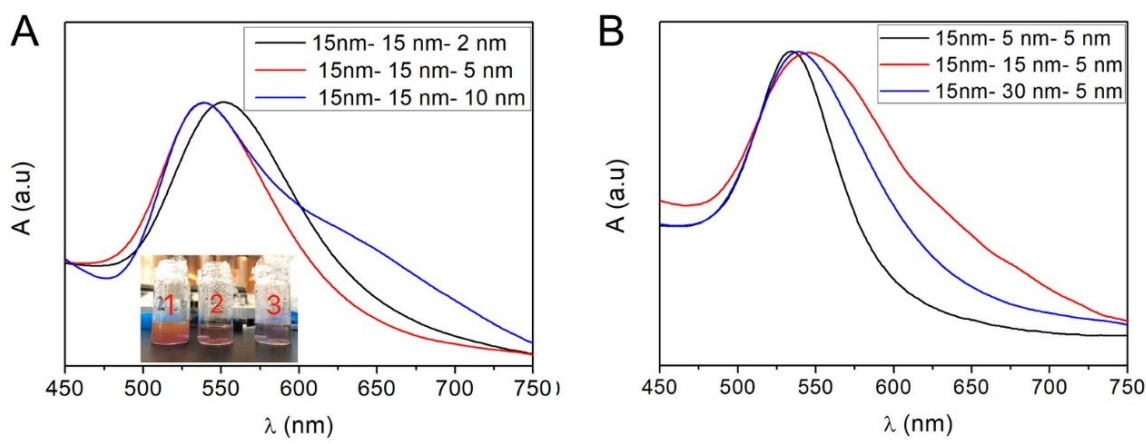

Figure 8. Experimental absorbance curves of $\mathrm{UCNP@mSiO} 2-\mathrm{Au} N P s$ (A) with different $\mathrm{Au}$ NPs added and (B) with different distance $D$ between the UCNPs and Au NPs. The inset figure of Figure 8A shows the corresponding $\mathrm{UCNP@mSiO} 2$-Au solutions with enhanced Au NPs.

Discrepancy in the absorption spectra may be explained by the different distribution of the $\mathrm{Au}$ NPs in the silica shell, which in the case of the synthesized Au NPs is dispersed. Uncertainty in the geometry of the deposited Au NPs on the surface of the mesoporous silica shell (including dispersion, number, and location) lead to inexact simulation results. First attempts to use more realistic geometries in the simulation failed so far. Still, the absorbance blue-shift of samples with more Au NPs added (Figure 8A) and the absorbance red-shift of samples with enhanced silica sizes (Figure 8B) qualitatively goes in the same direction as the simulated values (Figures 4 and 5). That means, DDA simulation needs to be refined taking better into account the distribution of the Au NPs for being better able to predict improved design of lanthanide@silica@Au NPs with optimized up-conversion luminescence intensity.

We tried another improved DDA model with the aim to be better consistent with the experimental results. Here, a modified DDA model of UCNP@ $\mathrm{mSiO}_{2}-\mathrm{Au}$ NPs with dispersed NPs in the shell instead of a full Au shell was carried out. As shown in Figure 9A, when there are more dispersed $\mathrm{Au}$ NPs in the shell, the SPR peak red-shifts in comparison to UCNP@mSiO $2-\mathrm{Au}$ NPs with less $\mathrm{Au}$ NPs (Note: dispersed Au NPs instead of Au shell). The electric field strength under the irradiation wavelength $\lambda_{\mathrm{exc}}=\lambda_{\mathrm{SPR}}(730 \mathrm{~nm}$ and $680 \mathrm{~nm}$, respectively, in case of more and medium dispersed $\mathrm{Au}$ NPs) further directly present higher energy in the UCNP@mSiO${ }_{2}-\mathrm{Au}$ NPs with more Au NPs (Figure 9B). If the amount of Au NPs would be much lower, the NIR peak and energy may disappear, and there is only one SPR peak at $520 \mathrm{~nm}$. These results may well explain why the experimental spectra has lower absorbance in the NIR region. That means, the DDA simulation could be suitable for guiding how the Au NPs effect the UCNPs if the DDA model would be improved.

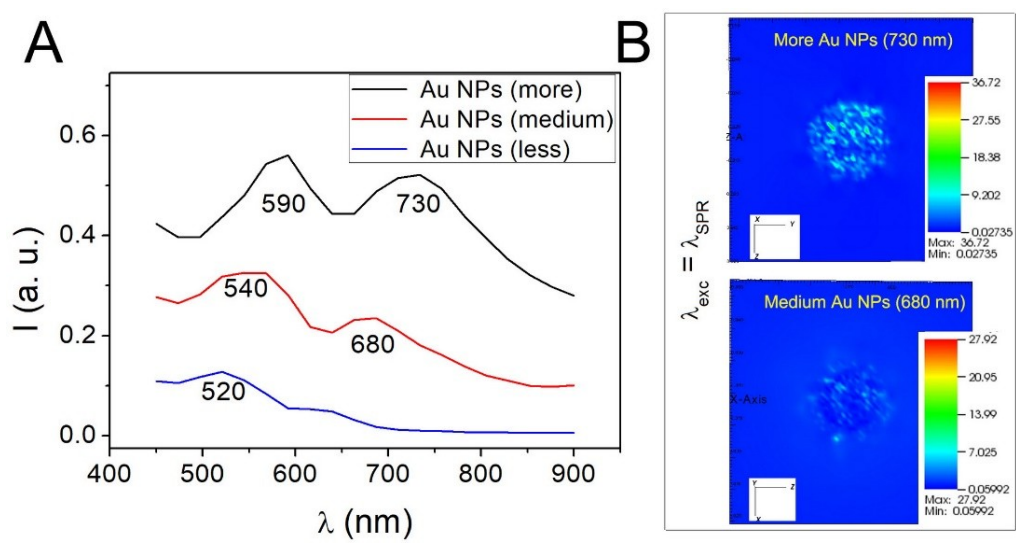

Figure 9. DDA results with dispersed Au NPs in the $5 \mathrm{~nm}$ Au shell. (A) The wavelength-dependence of extinction and (B) the electric field strength $\left(|E| /\left|E_{0}\right|\right)$ of $\mathrm{UCNP}_{\mathrm{mSiO}}-\mathrm{Au}$ NPs (15 nm-15 nm-5 nm geometry) under the irradiation wavelength $\lambda_{\mathrm{exc}}=\lambda_{\mathrm{SPR}}$. 


\section{Conclusions}

In this work we have fabricated lanthanide@silica@Au structures with enhanced UCL intensity. DDA simulation were used to guide the design. The final UCL enhancement factor is more than 2-fold when the distance between lanthanide and Au NPs is $30 \mathrm{~nm}$. The present study exemplifies the employment of theoretical approaches used to describe the optical properties to achieve better understanding of the behavior of lanthanide-metal hybrid nanoparticles, while pointing out also limitations of such modelling.

Supplementary Materials: The following are available online at http:/ /www.mdpi.com/2079-4991/8/12/989/s1, Table S1: The refractive index $n$ of $\mathrm{NaYF}_{4}$ in dependence of the wavelength; Table S2: The refractive index $\mathrm{n}$ of $\mathrm{SiO}_{2}$; Table S3: The refractive index $\mathrm{n}$ of Au, Figure S1: The refractive index $\mathrm{n}$ (real part) of $\mathrm{NaYF}_{4}, \mathrm{SiO}_{2}$, and $\mathrm{Au}$.

Author Contributions: All authors have given approval to the final version of the manuscript. Conceptualization, R.L.; Experiment, R.L. and M.F.; Data Curation, R.L.; Validation, W.J.P.; Writing-Original Draft Preparation, R.L.; Writing-Review \& Editing, W.J.P.

Funding: This research was funded by a postdoctoral fellowship from the Alexander von Humboldt Foundation, the Fundamental Research Funds for the Central Universities, the Natural Science Foundation of China (NSFC 81801744 and the Deutsche Forschungsgemeinschaft (DFG PA 794/28-1).

Conflicts of Interest: The authors declare no conflicts of interest.

\section{References}

1. Dai, Y.; Xiao, H.; Liu, J.; Yuan, Q.; Ma, P.A.; Yang, D.; Li, C.; Cheng, Z.; Hou, Z.; Yang, P.; et al. In Vivo Multimodality Imaging and Cancer Therapy by Near-Infrared Light-Triggered trans-Platinum Pro-Drug-Conjugated Upconverison Nanoparticles. J. Am. Chem. Soc. 2013, 135, 18920-18929. [CrossRef] [PubMed]

2. Lv, R.; Yang, P.; Hu, B.; Xu, J.; Shang, W.; Tian, J. In Situ Growth Strategy to Integrate Up-Conversion Nanoparticles with Ultrasmall CuS for Photothermal Theranostics. ACS Nano 2017, 11, 1064-1072. [CrossRef] [PubMed]

3. Gnach, A.; Lipinski, T.; Bednarkiewicz, A.; Rybka, J.; Capobianco, J.A. Upconverting nanoparticles: Assessing the toxicity. Chem. Soc. Rev. 2015, 44, 1561-1584. [CrossRef] [PubMed]

4. Chen, G.; Roy, I.; Yang, C.; Prasad, P.N. Nanochemistry and Nanomedicine for Nanoparticle-based Diagnostics and Therapy. Chem. Rev. 2016, 116, 2826-2885. [CrossRef] [PubMed]

5. Zhu, X.; Feng, W.; Chang, J.; Tan, Y.-W.; Li, J.; Chen, M.; Sun, Y.; Li, F. Temperature-feedback upconversion nanocomposite for accurate photothermal therapy at facile temperature. Nat. Commun. 2016, 7. [CrossRef] [PubMed]

6. Wang, J.; Deng, R.; MacDonald, M.A.; Chen, B.; Yuan, J.; Wang, F.; Chi, D.; Hor, T.S.A.; Zhang, P.; Liu, G.; et al. Enhancing multiphoton upconversion through energy clustering at sublattice level. Nat. Mater. 2014, 13, 157-162. [CrossRef] [PubMed]

7. Boyer, J.-C.; van Veggel, F.C.J.M. Absolute quantum yield measurements of colloidal $\mathrm{NaYF}_{4}: \mathrm{Er}^{3+}, \mathrm{Yb}^{3+}$ upconverting nanoparticles. Nanoscale 2010, 2, 1417-1419. [CrossRef] [PubMed]

8. Komban, R.; Klare, J.P.; Voss, B.; Nordmann, J.; Steinhoff, H.-J.; Haase, M. An Electron Paramagnetic Resonance Spectroscopic Investigation on the Growth Mechanism of NaYF4:Gd Nanocrystals. Angew. Chem. Int. Ed. 2012, 51, 6506-6510. [CrossRef] [PubMed]

9. Zhou, J.; Liu, Q.; Feng, W.; Sun, Y.; Li, F. Upconversion Luminescent Materials: Advances and Applications. Chem. Rev. 2015, 115, 395-465. [PubMed]

10. Yang, Y.; Liu, J.; Sun, X.; Feng, L.; Zhu, W.; Liu, Z.; Chen, M. Near-infrared light-activated cancer cell targeting and drug delivery with aptamer-modified nanostructures. Nano Res. 2016, 9, 139-148. [CrossRef]

11. Liu, J.; Bu, W.; Pan, L.; Shi, J. NIR-Triggered Anticancer Drug Delivery by Upconverting Nanoparticles with Integrated Azobenzene-Modified Mesoporous Silica. Angew. Chem. Int. Ed. 2013, 52, 4375-4379. [CrossRef] [PubMed]

12. Reineck, P.; Gibson, B.C. Near-Infrared Fluorescent Nanomaterials for Bioimaging and Sensing. Adv. Opt. Mater. 2017, 5. [CrossRef] 
13. Li, L.L.; Wu, P.W.; Hwang, K.; Lu, Y. An Exceptionally Simple Strategy for DNA-Functionalized Up-Conversion Nanoparticles as Biocompatible Agents for Nanoassembly, DNA Delivery, and Imaging. J. Am. Chem. Soc. 2013, 135, 2411-2414. [CrossRef] [PubMed]

14. Zeng, L.Y.; Pan, Y.W.; Zou, R.F.; Zhang, J.C.; Tian, Y.; Teng, Z.G.; Wang, S.J.; Ren, W.Z.; Xiao, X.S.; Zhang, J.C.; et al. $808 \mathrm{~nm}$-excited upconversion nanoprobes with low heating effect for targeted magnetic resonance imaging and high-efficacy photodynamic therapy in HER2-overexpressed breast cancer. Biomaterials 2016, 103, 116-127. [CrossRef] [PubMed]

15. Wang, D.; Xue, B.; Kong, X.; Tu, L.; Liu, X.; Zhang, Y.; Chang, Y.; Luo, Y.; Zhao, H.; Zhang, H. 808 nm driven $\mathrm{Nd}^{3+}$-sensitized upconversion nanostructures for photodynamic therapy and simultaneous fluorescence imaging. Nanoscale 2015, 7, 190-197. [CrossRef] [PubMed]

16. Zhong, Y.; Tian, G.; Gu, Z.; Yang, Y.; Gu, L.; Zhao, Y.; Ma, Y.; Yao, J. Elimination of Photon Quenching by a Transition Layer to Fabricate a Quenching-Shield Sandwich Structure for $800 \mathrm{~nm}$ Excited Upconversion Luminescence of $\mathrm{Nd}(3+)$-Sensitized Nanoparticles. Adv. Mater. 2014, 26, 2831-2837. [CrossRef] [PubMed]

17. Vetrone, F.; Naccache, R.; Mahalingam, V.; Morgan, C.G.; Capobianco, J.A. The Active-Core/Active-Shell Approach: A Strategy to Enhance the Upconversion Luminescence in Lanthanide-Doped Nanoparticles. Adv. Funct. Mater. 2009, 19, 2924-2929. [CrossRef]

18. Bigall, N.C.; Parak, W.J.; Dorfs, D. Fluorescent, magnetic and plasmonic-Hybrid multifunctional colloidal nano objects. Nano Today 2012, 7, 282-296. [CrossRef]

19. Cheng, L.; Wang, C.; Feng, L.Z.; Yang, K.; Liu, Z. Functional Nanomaterials for Phototherapies of Cancer. Chem. Rev. 2014, 114, 10869-10939. [CrossRef] [PubMed]

20. Mahmoud, M.A.; El-Sayed, M.A. Time dependence and signs of the shift of the surface plasmon resonance frequency in nanocages elucidate the nanocatalysis mechanism in hollow nanoparticles. Nano Lett. 2011, 11, 946-953. [CrossRef] [PubMed]

21. Skrabalak, S.E.; Chen, J.Y.; Sun, Y.G.; Lu, X.M.; Au, L.; Cobley, C.M.; Xia, Y.N. Gold Nanocages: Synthesis, Properties, and Applications. Acc. Chem. Res. 2008, 41, 1587-1595. [CrossRef] [PubMed]

22. Mahmoud, M.A.; Qian, W.; El-Sayed, M.A. Following charge separation on the nanoscale in $\mathrm{Cu}(2) \mathrm{O}-\mathrm{Au}$ nanoframe hollow nanoparticles. Nano Lett. 2011, 11, 3285-3289. [CrossRef] [PubMed]

23. Qian, J.; Jiang, L.; Cai, F.H.; Wang, D.; He, S.L. Fluorescence-surface enhanced Raman scattering co-functionalized gold nanorods as near-infrared probes for purely optical in vivo imaging. Biomaterials 2011, 32, 1601-1610. [CrossRef] [PubMed]

24. Xu, D.-D.; Deng, Y.-L.; Li, C.-Y.; Lin, Y.; Tang, H.-W. Metal-enhanced fluorescent dye-doped silica nanoparticles and magnetic separation: A sensitive platform for one-step fluorescence detection of prostate specific antigen. Biosens. Bioelectron. 2017, 87, 881-887. [CrossRef] [PubMed]

25. Shen, Y.Z.; Shuhendler, A.J.; Ye, D.J.; Xu, J.J.; Chen, H.Y. Two-photon excitation nanoparticles for photodynamic therapyt. Chem. Soc. Rev. 2016, 45, 6725-6741. [CrossRef] [PubMed]

26. Priyam, A.; Idris, N.M.; Zhang, Y. Gold nanoshell coated NaYF4 nanoparticles for simultaneously enhanced upconversion fluorescence and darkfield imaging. J. Mater. Chem. 2012, 22, 960-965. [CrossRef]

27. Sudheendra, L.; Ortalan, V.; Dey, S.; Browning, N.D.; Kennedy, I.M. Plasmonic Enhanced Emissions from Cubic $\mathrm{NaYF}_{4}: \mathrm{Yb}: \mathrm{Er} / \mathrm{Tm}$ Nanophosphors. Chem. Mater. 2011, 23, 2987-2993. [CrossRef] [PubMed]

28. Lv, R.; Yang, P.; Dai, Y.; Gai, S.; He, F.; Lin, J. Lutecium Fluoride Hollow Mesoporous Spheres with Enhanced Up-Conversion Luminescent Bioimaging and Light-Triggered Drug Release by Gold Nanocrystals. ACS Appl. Mater. Interfaces 2014, 6, 15550-15563. [CrossRef] [PubMed]

29. Lv, R.; Yang, G.; Dai, Y.; Gai, S.; He, F.; Yang, P. Self-produced bubble-template synthesis of $\mathrm{La}_{2} \mathrm{O}_{3}: \mathrm{Yb} / \mathrm{Er} @ \mathrm{Au}$ hollow spheres with markedly enhanced luminescence and release properties. Crystengcomm 2014, 16, 9612-9621. [CrossRef]

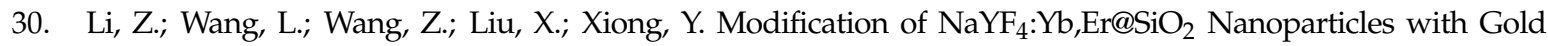
Nanocrystals for Tunable Green-to-Red Upconversion Emissions. J. Phys. Chem. C 2011, 115, 3291-3296. [CrossRef]

31. Ge, W.; Zhang, X.R.; Liu, M.; Lei, Z.W.; Knize, R.J.; Lu, Y. Distance Dependence of Gold-Enhanced Upconversion luminescence in $\mathrm{Au} / \mathrm{SiO}_{2} / \mathrm{Y}_{2} \mathrm{O}_{3}: \mathrm{Yb}^{3+}, \mathrm{Er}^{3+}$ Nanoparticles. Theranostics 2013, 3, 282-288. [CrossRef] [PubMed]

(C) 2018 by the authors. Licensee MDPI, Basel, Switzerland. This article is an open access article distributed under the terms and conditions of the Creative Commons Attribution (CC BY) license (http:/ / creativecommons.org/licenses/by/4.0/). 